\title{
MOLECULAR CLONING OF Elaeis guineensis PHYTOENE SYNTHASE (Egpsy) AND ITS EXPRESSION IN MESOCARP TISSUES
}

\author{
WAN NUR SYUHADA, W S ${ }^{1 *}$; RASID, O A ${ }^{1}$ and GHULAM KADIR AHMAD PARVEEZ ${ }^{1}$
}

\begin{abstract}
Phytoene synthase (psy) gene is responsible for the synthesis of carotenoids in plants. In this study complimentary deoxyribonucleic acid (cDNA) and genomic sequences of psy were isolated by rapid amplification of $c D N A$ ends and polymerase chain reaction (PCR) using ribonucleic acid (RNA) and DNA isolated from the mesocarp tissues of oil palm (Elaeis guineensis). The size of the full-length $c D N A$ was $2233 \mathrm{bp}$. The open reading frame (ORF) was $1299 \mathrm{bp}$ and encoded 433 deduced amino acid (AA) residues. The transcript profile revealed that psy was expressed at a maximum level at 12 weeks after anthesis (WAA). The lowest expression of psy was at 13 WAA, which was speculated as the transition of the leaf-like carotenoid to the formation of storage carotenoids. The AA sequence deduced from the cDNA was $70 \%$ 78\% identical to PSY from other higher plants. The genomic sequence analysis revealed that the psy gene contains six exons and five introns. Southern blot analysis indicated that oil palm has only one copy of the psy gene in its genome.
\end{abstract}

Keywords: carotenoids, oil palm, phytoene synthase (psy).

Received: 5 August 2020; Accepted: 21 October 2020; Published online: 17 December 2020.

\section{INTRODUCTION}

In 2018, palm oil was a major edible vegetable oil, contributing about $34 \%$ of the world's vegetable oils consumption and produced mostly in Malaysia and Indonesia (Kushairi et al., 2019). Crude palm oil is considered as the world's richest natural plant source of carotenoids. Malaysian crude palm oil contains typically 500-700 parts per million (ppm) of carotenoids (Mustapa et al., 2011). Carotenoids such as $\beta$-carotene, lycopene and lutein found in vegetable oils, possess anti-oxidant, anticarcinogenic activities (Uenojo et al., 2007) and provide a primary dietary source of provitamin A in human diets (Tanaka and Ohmiya, 2008). Its deficiency could lead to blindness and premature death (Mayne, 1996). Besides their health-

\footnotetext{
Malaysian Palm Oil Board,

6 Persiaran Institusi, Bandar Baru Bangi,

43000 Kajang, Selangor, Malaysia.

* Corresponding author e-mail: syuhada@mpob.gov.my
}

promoting roles, carotenoids are economically important natural products used mainly in food, animal feed, pharmaceutical, nutraceutical and cosmetic industries. In higher plants, carotenoids are essential for providing photoprotective functions during photosynthesis and as precursors for abscisic acid (ABA) biosynthesis.

Gene cloning and functional research of the carotenoid biosynthesis pathway have been extensively carried out in many photosynthetic and non-photosynthetic organisms. The pathway of carotenoid biosynthesis was elucidated in 1987, starting with phytoene synthase ( $p s y)$ in tomato (Zhang et al., 2016). The enzyme catalyses the first step in the synthesis to produce phytoene from geranylgeranyl pyrophosphate (ggpp). Phytoene undergoes a series of four desaturations that result in the formation of lycopene. In higher plants, these steps are catalysed by two enzymes, phytoene desaturase $(p d s)$ and $\xi$-carotene desaturase. Lycopene undergoes cyclisation by lycopene epsilone cyclase (lcye) and lycopene $\beta$-cyclase 
$(l c y b)$ to produce $\alpha$ - and $\beta$-carotenes. Subsequent hydroxylation reactions produce zeaxanthin and lutein (Nisar et al., 2015).

The molecular basis of oil palm carotenoid synthesis has received little attention compared to other higher plants such as tomato (Solanum lycopersicum). Tomato is a well-established model plant for carotenoid biosynthesis in fleshy fruit. It has the wealth of genome resources and genetic transformability. However, it is not considered as a comparative reference to study the transcriptional regulation of carotenoid synthesis pathway especially in oil fruits such as oil palm (Tranbarger et al., 2011). The oil palm (Elaeis guineensis) genome has been reported (http://genomsawit.mpob.gov. my/). The genome data will be a helpful resource to identify key genes involved in its carotenoid metabolism (Singh et al., 2013). To date, only seven of the oil palm carotenoid genes have been reported, namely, pds (Rasid et al., 2005), lcyb (Rasid et al., 2003; 2009), 1-deoxy-D-xylulose 5-phosphate synthase (dxs) and 1-deoxy-D-xylulose 5-phosphate reductoisomerase (dxr) (Khemvong and Suvachittanont, 2005), zeta-carotene desaturase (zds) (Rasid et al., 2005), full length of lcye (Rasid et al., 2009) and psy from Elaeis oleifera (Wan Nur Syuhada et al., 2012; Rasid et al., 2008).

Geranylgeranyl pyrophosphate $(g g p p)$ is the main precursor for carotenoid biosynthesis in plants. However, this precursor is also shared with other vital metabolic pathways including the synthesis of gibberellic acid, chlorophylls, plastoquinones and tocopherols. Therefore, modifying the carotenoid content and/or composition could have potential negative effects on plant growth (Tanaka and Ohmiya, 2008). Since ggpp serves as a precursor for other metabolic pathways, PSY plays an important role in controlling the flux (of carbon) in the carotenoid biosynthetic pathway (Lopez-Emparan et al., 2014). The transcription of psy genes has been shown to respond to ABA, salt, light, temperature, drought, photoperiod, development cues and post-transcriptional feedback regulation (Cazzonelli and Pogson, 2010). This enzyme has been isolated previously from a range of plant species including tomato (Ray et al., 1992; Fray and Grierson, 1993; Giuliano et al., 1993; Misawa et al., 1994; Fraser et al., 1995), Arabidopsis thaliana (Scolnik and Bartley, 1994), tobacco (Busch et al., 2002), maize (Buckner et al., 1996; Wong et al., 2004), melon (Karvouniet al., 1995), citrus (Kim et al., 2001; Kato et al., 2004; Rodrigo et al., 2004), pepper (Huh et al., 2001), sunflower (Salvini et al., 2005) and banana (Mlalazi et al. 2012). The modification of this gene could be effective and useful for increasing carotenoid content in industrial crops. In order to study metabolic pathways especially the carotenoid pathway, genes are usually organised in operons. This operon will be inserted into plastid deoxyribonucleic acid (DNA) and then coexpressed as polycistronic transcripts. These transcripts are often processed further into monocistronic messenger ribonucleic acid (mRNA). For example, Golden rice 2 was developed by introducing maize psy in combination with Erwinia uredovora carotene desaturase $(c r t l)$. The amount of $\beta$-carotene in the endosperm was increased up to $37 \mu \mathrm{g} \mathrm{g}^{-1}$ of the $31 \mu \mathrm{g} \mathrm{g}^{-1}$ of carotenoids. It is equivalent to the recommended level of vitamin A for a day (Paine et al., 2005).

Manipulation of $p s y$ in oil palm could potentially increase its carotenoid content as well as alter its composition. However, the molecular basis for the oil palm psy is currently unknown especially in E. guineensis. Thus, isolation of this gene will enable the investigation of its role in the carotenoid biosynthesis pathway. In this article, we report the isolation and characterisation of psy gene from oil palm (E. guineensis). The full length of psy complimentary DNA (cDNA) and its genomic sequence were successfully isolated and characterised. The molecular phylogeny of psy and its expression in mesocarp tissues at different developmental stages were determined.

\section{MATERIALS AND METHODS}

\section{Plant Materials}

Oil palm fruits were collected from a field at Malaysian Palm Oil Board (MPOB), Bangi, Selangor, Malaysia. The mesocarp tissues at different fruit developmental stages, namely at 5, 7, 9, 11, 13, 15, 17 and 19 weeks after anthesis (WAA), were harvested for ribonucleic acid (RNA) isolation. Total RNA was extracted from the mesocarp tissues of oil palm according to Zeng and Yang (2002). Total DNA from mesocarp tissue was extracted using the modified cetyl trimethylammonium bromide (CTAB) method (Stewart and Via, 1993). The concentration and quality of the RNA and DNA were determined by spectrophotometer and agarose gel analysis. The DNA and RNA samples were stored at $-20^{\circ} \mathrm{C}$ and $-80^{\circ} \mathrm{C}$, respectively, prior to further analysis.

\section{Reverse Transcription of mRNA and Reverse Transcription Polymerase Chain Reaction (RT- PCR)}

The first-strand cDNA was synthesised from $1 \mu \mathrm{g}$ of total RNA sample using the SMART ${ }^{\mathrm{TM}}$ RACE cDNA Amplification Kit (Clontech, USA) according to the manufacturer's instructions. The synthesised cDNA was stored at $-20^{\circ} \mathrm{C}$ for PCR amplification. 
The primers used in the initial reverse transcription PCR (RT-PCR) amplification were designed by using the COnsensus- DEgenerate Hybrid Oligonucleotide Primer (CODEHOP) (Rose et al., 2005). The software is available at http:/ / blocks.fhrcc.org/ codehop.html. Primer sequences were as follows: the sense primer: 5'-GGTGTACAACGTGGTGCTGAARCARGCN GC-3' and the antisense primer: 5'-TGAA GTTGTTGTAGTCGTTGGCYTCDATYTC-3'. RT-PCR amplifications were performed using AccuPrime $^{\mathrm{TM}}$ Taq DNA Polymerase System Kit (Invitrogen). The amplifications were carried out in a PTC-100 Thermocycler (MJ Research, USA), in 30-35 sequential cycles programmed as follows: initial denaturing cycle at $94^{\circ} \mathrm{C}$ for $30 \mathrm{~s}, 30 \mathrm{~s}$ annealing at $55^{\circ} \mathrm{C}-60^{\circ} \mathrm{C}, 2 \mathrm{~min}$ elongation at $68^{\circ} \mathrm{C}$ and a final cycle of $7 \mathrm{~min}$ at $68^{\circ} \mathrm{C}$.

The 5' RACE primers (PSY15, 5'-TTGGCATA CTCTGCACAGACTTC-3' and PSY19, 5'-TA GCCGAAGGCGTAATGTGAGAAGC-3') were designed and synthesised based on the partial sequence of the initial amplified product. Then, the 5' RACE PCR was performed according to the protocol of the SMART ${ }^{\mathrm{TM}}$ RACE CDNA Amplification Kit (Clontech, USA). The first-round PCR was carried out with PSY15 and Universal Primer Mix (UPM) primer set, and the nested-PCR with PSY19 and nested UPM (NUPM) primer set. The nested-PCR product was purified and cloned into PCRII-TOPO vector (TOPO TA Cloning Kit, Invitrogen, USA) and sequenced.

End-to-end PCR was performed to amplify the complete cDNA and genomic sequence of $p s y$ using the gene-specific primers (PSYA1 and PSYAB4) that were designed based on $5^{\prime}$ and $3^{\prime}$ regions.

\section{Bioinformatics Analysis}

The AA sequence analyses were performed using open reading frame (ORF) Finder (http:/ / www.ncbi.nlm.nih.gov/gorf/gorf.html). Comparison of the sequence was performed by using BLAST of GenBank (http: / / www.ncbi.nlm. nih.gov/BLAST/). Multiple sequence alignment was carried out using Vector NTI software. Predictionof signal peptide was performed with SIGNALP. Full sequences were aligned using ClustalW ver. 2.1, while phylogenetic analysis was done using RAxML (General time reversible nucleotide substitution model with gamma distributed rate variation among sites and Felsenstein's bootstraps) visualisation with ClustalW by ETE3. Protein localisation site was predicted by Wolf PSORT program (Horton et al., 2007). The presence of transmembrane domain was analysed by TMpred algorithm (http: / www. ch.embnet.org/software/TMPRED_form.html).

\section{Southern Blot Analysis}

A total of $30 \mu \mathrm{g}$ of genomic DNA were digested with BamHI, HindIII, EcoRI and SpeI, separated on a $0.9 \%$ agarose gel and transferred onto Hybond XL membrane (Amersham Bioscience). A specific primed DNA probe was synthesised from the E. guineensis phytoene synthase (Egpsy) cDNA using the TAKARA random primer (TAKARA) according to the manufacturer's instructions. The membrane was hybridised at $60^{\circ} \mathrm{C}$ with $\alpha-^{32} \mathrm{P}$-dCTP-labelled probe. After hybridisation, the membrane was washed in $2 \times \mathrm{SSC} / 0.1 \%$ SDS at $60^{\circ} \mathrm{C}$ for $10 \mathrm{~min}$ followed by $1 \times \mathrm{SSC} / 0.1 \% \mathrm{SDS}$ at $60^{\circ} \mathrm{C}$ for $10 \mathrm{~min}$.

\section{Reverse Transcription Quantitative Real-time PCR (RT-qPCR)}

The expression study of oil palm psy was performed using reverse transcription quantitative real-time PCR (RT-qPCR) analysis. Total RNA from mesocarp of 5-19 WAA fruits were used in the analysis. Total RNA (10 $\mu \mathrm{g})$ was reverse transcribed with the High Capacity cDNA Archive Kit (Applied Biosystem) according to the manufacturer's protocol. The cDNA (100 ng) was subjected to qPCR assays in triplicate on an ABI PRISM 7000 Sequence Detection System (Applied Biosystems, USA) using TaqMan Universal PCR mastermix according to the manufacturer's recommendation (Applied Biosystems, USA). The primers for the $p$ sy gene were CGGATCTAGTGAGTTGTTCTTCGA(forward)and GGAATTATGCTGTATATACCATATCCGCAAT (reverse) and the probe for the gene was F A M - C T C G G A A C A A C A A G A T C - N F Q. Meanwhile, the primers for the GAPDH were ACTGCTACTCAGAAGACTGTTGATG (forward) and TGCTGCTAGGAATGATGTTAAAGCT (reverse) and the probe for the gene was FAMACCCCTCCAGTCCTTG-NFQ. PCR cycling parameters were set at one cycle of $50^{\circ} \mathrm{C}$ for $2 \mathrm{~min}$, $95^{\circ} \mathrm{C}$ for $10 \mathrm{~min}$ and then 40 cycles of $95^{\circ} \mathrm{C}$ for $15 \mathrm{~s}$ and $60^{\circ} \mathrm{C}$ for $1 \mathrm{~min}$. Data was acquired and analysed by using the ABI PRISM 7000 Sequence Detection System software (Applied Biosystems, USA).

The expression profile of each cDNA was studied by the relative quantification of the mRNA using the comparative $\Delta \Delta C_{T}$ method (Livak and Schmittgen, 2001). First, the threshold cycle $\left(C_{T}\right)$ value for each sample and its replicates was obtained from the amplification plots. The value represents the cycle at which the signal is first recorded as statistically significant above the background. Then, the average $C_{T}$ values for the target gene in each of the samples were determined from replicates. This was carried out for both the target genes and the internal control glyceraldehyde 3-phosphate dehydrogenase (GAPDH). These values were normalised against 
the average $C_{T}$ values of the internal control $\left(\Delta C_{T}\right)$. The difference in $C_{T}$ values $\left(\Delta C_{T}\right)$ is equal to the difference in expression after being normalised to the endogenous control.

\section{RESULTS AND DISCUSSION}

\section{Isolation of Egpsy}

PSY is located in the chloroplast (Fraser et al., 2000) and it catalyses the first committed step of the carotenoid pathway that converts two molecules of ggpp into phytoene. This two-step conversion reaction is considered as a rate-limiting step in the pathway (Cunningham and Gantt, 1998). Consequently, psy has become the key target for genetic manipulation in many crop plants to increase the carotenoid content (Fraser et al., 2002; Fray et al., 1995).

In this work, psy cDNA was isolated from E. guineensis using degenerate primers (PSY5 and PSY6). A full-length cDNA encoding psy was obtained and designated as Egpsy. The gene reported in this article has been submitted to the PalmXPlore database (http://palmxplore. mpob.gov.my/) under the accession number p5.00_sc00017_p0037. The complete Egpsy has an ORF of $1299 \mathrm{bp}$ which is preceded by 346 bases of 5-untranslated region (5-UTR) followed by 588 bases of the 3'- UTR (Figure 1). Interestingly, Wan Nur Syuhada et al. (2012) also reported that psy from Elaeis oleifera and Egpsy nucleotide sequences were highly conserved at about $98 \%$. The BlastP search results demonstrated that the Egpsy clone showed a high sequence identity to PSY from other monocots, such as Phoenix dactylifera $(91.16 \%)$ and Musa AAB Group (79.35\%). Overall, the Egpsy sequence has a high degree of similarity with various species of plants $(80.00 \%)$, alga $(60.00 \%)$ and cyanobacteria $(40.00 \%)$ but not with bacteria and fungi $(16.90 \%)$.

The PCR product was also amplified directly from genomic DNA, sequenced on both strands and assembled using standard techniques. The total length of Egpsy genomic clone was $4342 \mathrm{bp}$, consisting of six exons and five introns. The sizes and organisation of the exons and introns are summarised in Figure 1. Comparatively, the number of exons and introns in Egpsy is similar to the psy from wheat and maize (Wang et al., 2009; Li et al., 2008).

\section{Egpsy Sequence Analyses}

In plants, the synthesis of carotenoids occurs in plastids. Thus, the enzymes involved in the pathway should contain plastid targeting signal for their transport into the plastids. Therefore, we looked for the plastid targeting signal using SIGNALP software and protein localisation using WoLF PSORT program (Horton et al., 2007). The SIGNALP software predicted a 12 -amino acid signal peptide with a molecular mass of $48.83 \mathrm{kDa}$ and an isoeletric point of 9.09. The WoLF PSORT program suggested that Egpsy might be localised in chloroplast and the protein feature had a similarity of about 69\% with PSY from Arabidopsis thaliana (https://www.uniprot.org/uniprot/P37271). This result may indicate that Egpsy is needed for photosynthesis and photoprotection function.

In order to examine the properties and conserved domains of the enzyme, the protein sequence was subjected to National Centre for Biotechnology Information (NCBI) Conserved Domain Search. We found that the protein has a single large prenyltransferase catalytic domain that belongs to the Trans-Isoprenyl Diphosphate, Head-to-Head $\left(1^{\prime}-1\right)$ condensation reaction (Trans_IPPS_HH) family (NCBO CDD No. cd00683) (Marchler-Bauer et al., 2011). Analysis of the sequence also indicated the presence of other features corresponding to the Trans-Isoprenyl Diphosphate Synthases family. This domain is present in all PSY, which catalyse the head to head $\left(1^{\prime}-1\right)$ condensation of two ggpp molecules to produce phytoene (C30 and C40) (Figure 2). The analysis also indicated the presence of major aspartate-rich motifs that are thought to be responsible for substrate binding. This result was also confirmed through transmembrane region analysis of the sequence using TMpred algorithm. The result showed two strong transmembrane helices, in-to-outside from 3-24 residues and outto-inside from 257-259 residues. The active site of the enzyme is hydrophobic and located within the transmembrane helical bundle where carbocation is generated, leaving the diphosphate group attached (Zviling et al., 2007). Meanwhile, Lopez-Emparan et al. (2014) reported Brassica napus L. PSY also had a conserved trans-IPP region and several motives

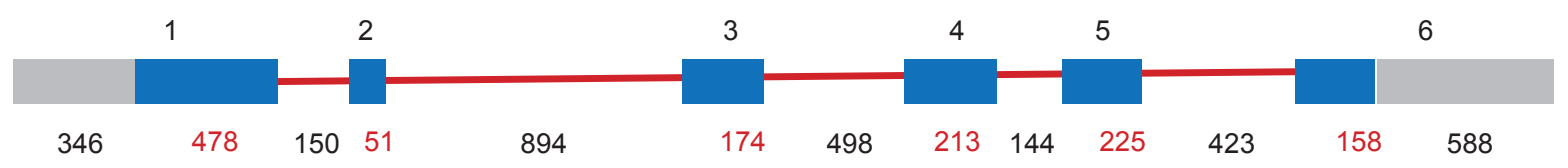

Figure 1. Diagram of exons and introns of Elaeis guineensis phytoene synthase (Egpsy). Grey and blue bars indicate untranslated and coding region, respectively. Meanwhile, thin red lines indicate introns and the number below them indicate their sizes in basepairs. 
E.guineensis aa Carica papaya Citrus sinensis Citrus unshiu Daucus carota N.pseudonarcissus Narcissus tazetta Oncidium Gower Ramsey Consensus

E.guineensis a Carica papaya Citrus sinensis

Citrus unshiu

Daucus carota

N.pseudonarcissus Narcissus tazetta Oncidium Gower Ramsey Consensus

E.guineensis aa Carica papaya Citrus sinensis

Citrus unshiu

Daucus carota

N.pseudonarcissus

Narcissus tazetta Oncidium Gower Ramsey Consensus

E.guineensis aa Carica papaya

Citrus sinensis

Citrus unshiu

Daucus carota

N.pseudonarcissus

Narcissus tazetta Oncidium Gower Ramsey Consensus

E.guineensis aa Carica papaya Citrus sinensis

Citrus unshiu

Daucus carota

N.pseudonarcissus

Narcissus tazett Oncidium Gower Ramsey Consensus

E.guineensis a Carica papaya

Citrus sinensis

Citrus unshiu Daucus carota

N.pseudonarcissus Narcissus tazetta Oncidium Gower Ramsey Consensus

E. guineensis aa Carica papaya Citrus sinensis Citrus unshiu Daucus carota

N.pseudonarcissu Narcissus tazetta Oncidium Gower Ramsey Consensus

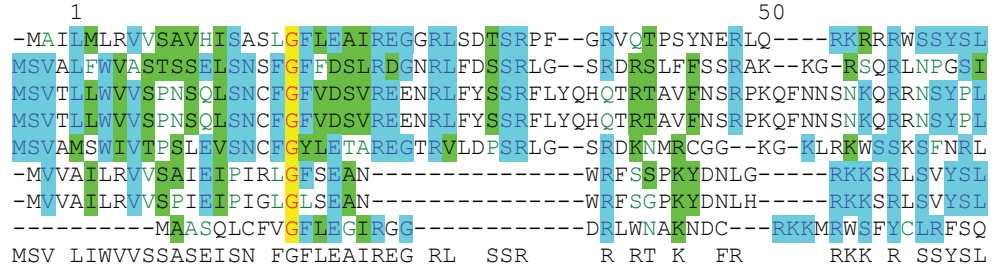

100
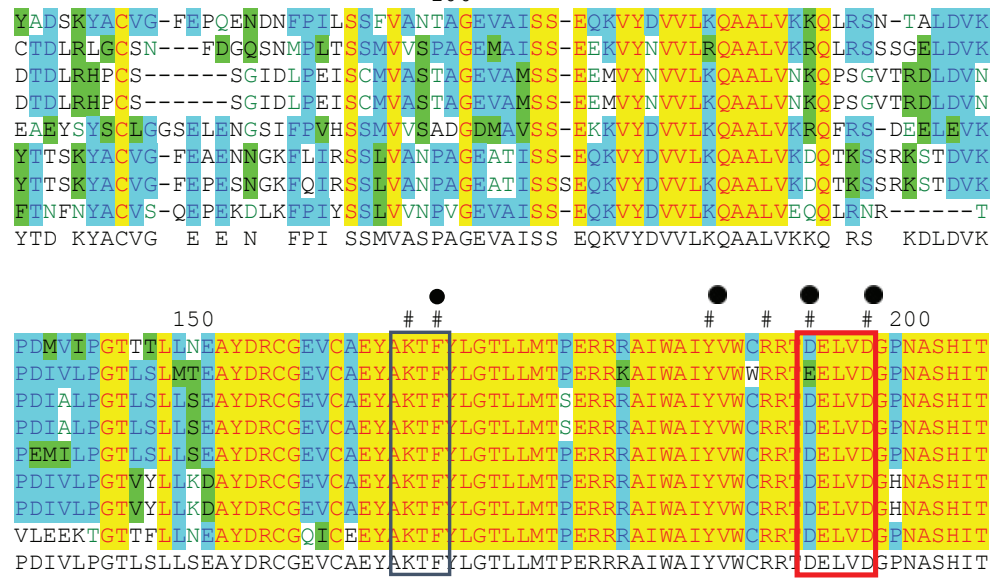

250

PSALDRWEARLEDLEAGRPYDMFDAALSHTVSKFPVDIQPFKDMIEGMRMGLKKSRYNNFDELYLYCY PTALDRWEARLEDLFQGRP FDMLDAALSDTVAKFPVDIQPF IDMI EGMRMDIRKSRYKNEDELYLYCY PTALDRWESRLEDLFRGRPFDMLDAALSDTVTKFPVDIQPFRDMIEGMRMDLRKSRYKNFDELYLYCY PTALDRWESRLEDLFRGRP FDMLDAALSDTVTKFPVDIQPFRDMIEGMRMDLRKSRYKNFDELYLYCY PSALDRWELRLEDLFKGRP FDMLDAAL SDTVMKFPVDIQPFKDMI EGMRMDLKKSRYKNFDELYLYCY PSALDRWEARLEDLFAGRPYDMFDAALSDTVSRFPVDIQPFMDMVEGMRMDLKKSRYKNFDELYLYCY PSALDRWEARLEDLF DGRPYDMFDAALSDTVSRFPVDIQPFMDMVEGMRMDLKKSRYKNFDELYLYCY PSALDRWEARLEDLFAGRPYDMLDASLSDTVVNFPVDIQPFKDMIEGMRMDLKKSRYKNFDELYLYCY PSALDRWEARLEDLF GRPFDMLDAALSDTVSKFPVDIQPFKDMIEGMRMDLKKSRYKNFDELYLYCY
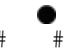

300

$\#$

YVAGTVGTMSVPTMCTA PESOATTESVYNAATALGTANOL IN LR PVGEDARRGR IY LPQDELAQAG YVAGTVGLMSVPVMGIAPDSQATTE SVYNAALALG IANQLTNI LR DVGEDARRGRVYLPQDELAQAGT YVAGTVGLMSVPVMG IAPDSQATTESVYNAALALGIANQLTNI LR PVGE D ARRGRVYLPQDELAQAGI
YVAGTVGLMSVPVMG IAPDSQATTESVYNAALALGIANQLTNI LR VVGE D ARRGRVYLPQDELAQAGI YVAGTVGLMSVP IMG IAPNSQATTESVYNAALALGLANQLTNI LR PVGE DARRGRVYLPQDELAQAGI YVAGTVGLMSVPVMG IAPESLAEAESVYNAALALGIANQLTNI LR DVGE DARRGR IYLPQDELAEAGI YVAGTVGLMSVPVMG IAPESLAEAESVYNAALALG IANQ LTN I LR DVGE DARRGR IYLPQDELAEAGE YVA GTVGLMSVPVMG IDPESDATTE SVYNAALS L G IANQLTNI LR VVGED PRRGRVY LPQDELAEAGL
YVAGTVGLMSVPVMG IAPESQATTESVYNAALALG IANQLTNI LR VVGEDARRGR IY LPQDELAQAGL

$$
\text { \#\# } 400
$$$$
350
$$

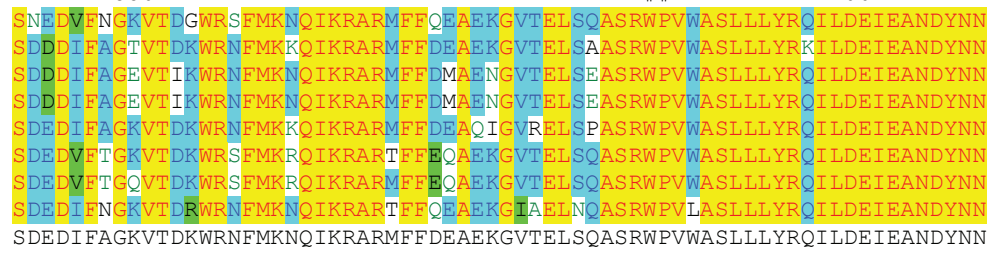

447
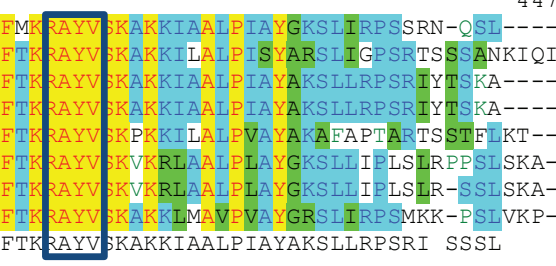

ATARTLIRPSHKR-PSLVKP-

Figure 2. Amino acid sequence alignment of phytoene synthase (PSY) from oil palm and PSY from several other plants. Yellow colour shows highly conserved amino acid residues. Numbers above the alignment indicate the amino acid positions along the Egpsy protein. The two aspartaterich regions $(D X X X D)$ and substrate- $\mathrm{Mg}^{2+}$ binding site are indicated in red box. The active site lid residues are indicated in blue box. The substrate binding pocket are indicated (\#). The catalytic residues are indicated $(\bullet)$. The sequences used in this analysis were as follows: Carica papaya (GenBank accession No. NW_019019210), Citrus sinensis (GenBank accession No. NM_001288886, Daucus carota subsp. Sativus (GenBank accession No. NM_001329167), Narcissus pseudonarcissus (GenBank accession No. X78814), Narcissus tazetta (GenBank accession No. DQ984674, Oncidium Gower Ramsey (GenBank accession No. FJ859988). 
such as plastid transit peptide and a putative psy active site (DXXXD) with conserved aspartate residues which was similar to Egpsy.

The deduced AA sequence for Egpsy was also subjected to phylogenetic analysis using ClustalW by ETE3. The sequence was compared with its respective orthologues (Figure 3). The phylogeny is rooted on the branch joining the outgroup to other sequences. PSY sequences were shown to fall into three defined clusters. One comprises the enzymes from cyanobacteria. The other clusters comprise of algae and higher plants. Egpsy has high identity with PSY sequences from the higher plants. The phylogenetic tree indicates that PSY sequences from higher plants, algae and cyanobacteria have clear divergence from each other. In higher plants, Egpsy is categorised into the monocot group together with Phoenix dactylifera, commonly known as date palm. This result showed that the PSY sequences from these two palm plants were closely related to each other. Bourgis et al. (2011) and Singh et al. (2013) also reported that oil palm and date palm nucleotide sequences were highly conserved which was about $92.0 \%-94.4 \%$ identity. Interestingly, these two palms showed a completely different carbonpartitioning pattern with oil palm mesocarp containing mostly lipid while date mesocarp accumulates mostly sugars.

\section{Southern and Expression Analyses}

The copy number of Egpsy gene in the E. guineensis genome was examined by performing Southern blot hybridisation. Using the $1.3-\mathrm{kb}$ coding region of Egpsy as a probe, Southern blot analysis revealed the hybridisation pattern of 1-3 bands per lane (Figure 4). However, a single major hybridisation band was observed for two of the digestions, namely BamHI $(\sim 7 \mathrm{~kb})$ and EcoRI $(\sim 5$ $\mathrm{kb})$. Digestion using HindIII and SpeI produced two $(\sim 3 \mathrm{~kb}$ and $\sim 6 \mathrm{~kb})$ and three $(\sim 1 \mathrm{~kb}, \sim 3 \mathrm{~kb}$ and $\sim 4 \mathrm{~kb})$ major hybridisation bands, respectively. The three sites of SpeI were located in the intron whereas HindIII was in exon 5 (Figure 1). Overall, the result

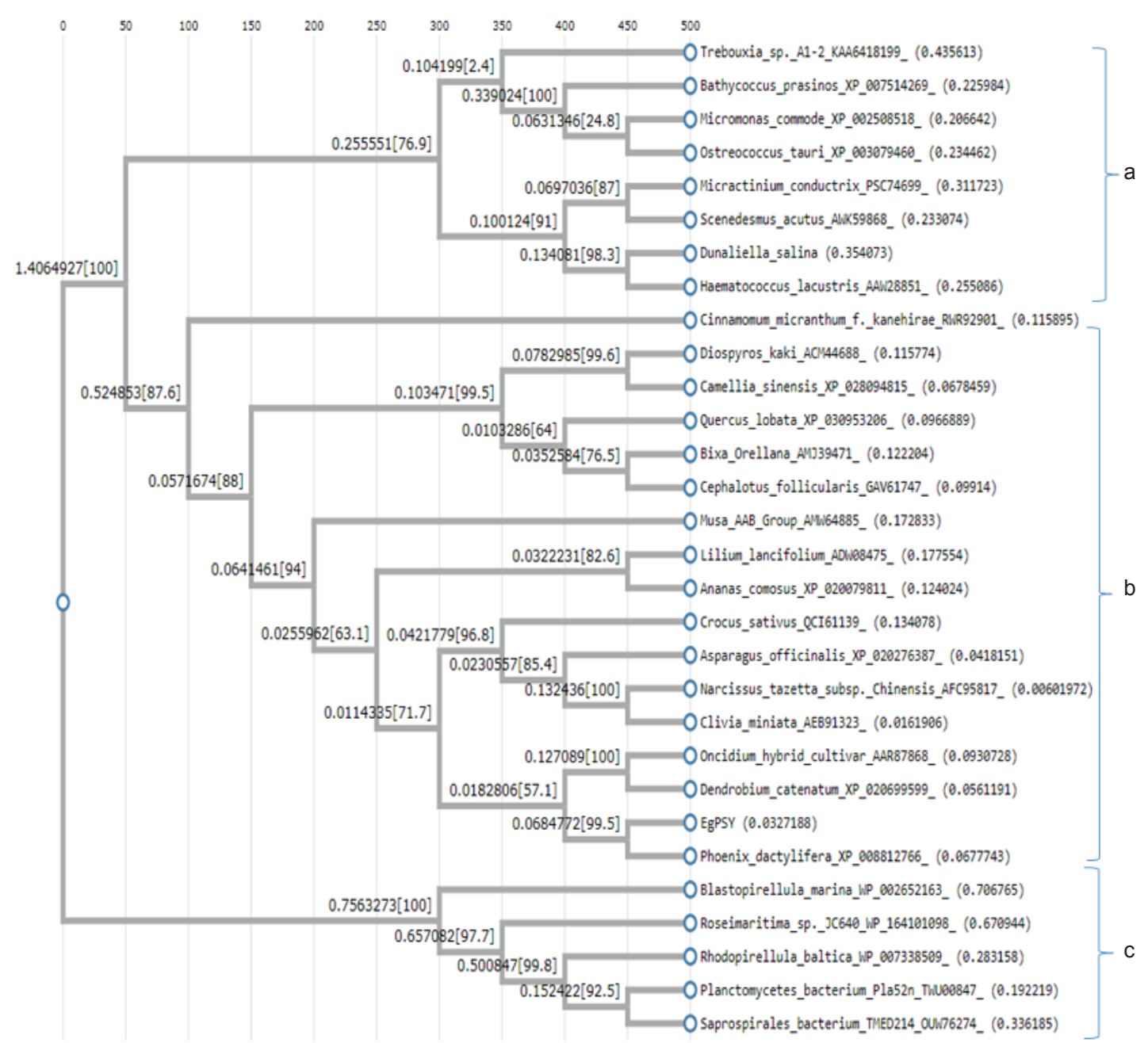

Figure 3. Phylogeny of phytoene synthase (PSY) amino acid sequences. The value at the nodes and branches represent the length of each branch. The values in bracket indicate the bootstrap support of each branch. The main clades labelled alga (a), plant (b) and cyanobacteria (c). The GenBank accession numbers are indicated at the end of the species names. 
(a)

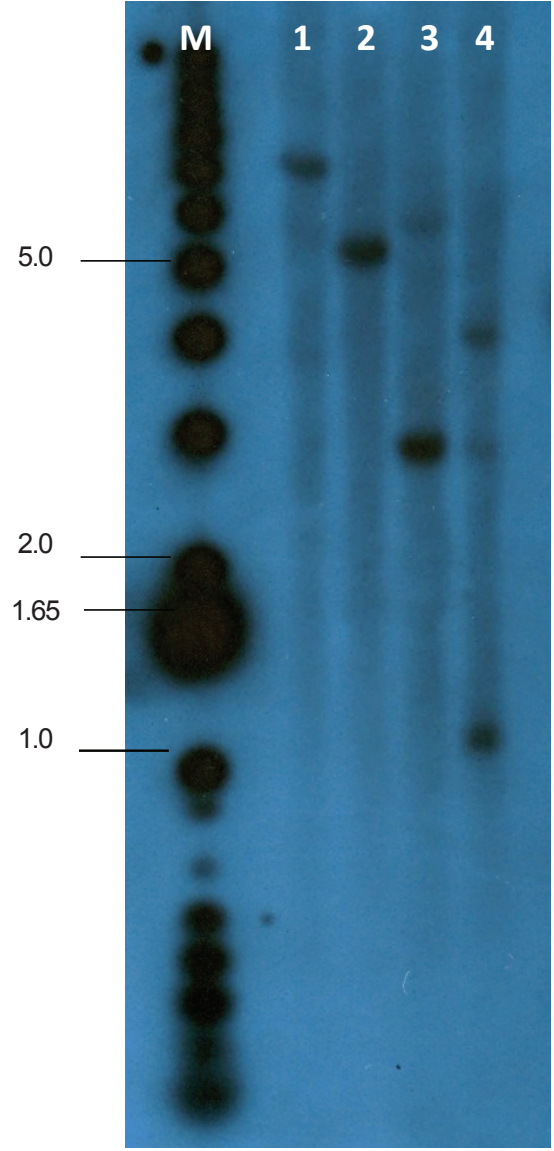

(b)

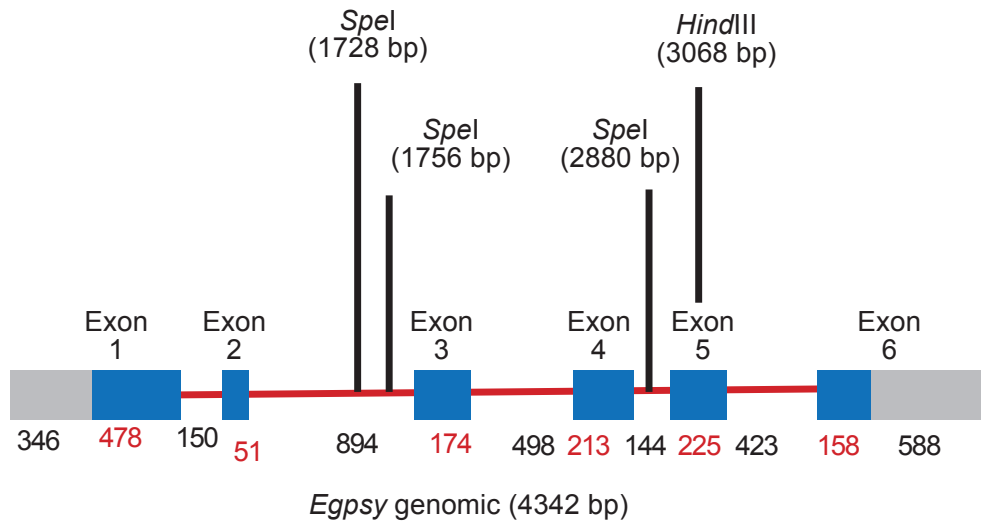

Figure 4. Southern blot analysis of E. guineensis phytoene synthase (Egpsy). (a) Thirty micrograms of total DNA of E. guineensis were digested using four different restriction enzymes namely BamHI, EcoRI, HindIII, and SpeI. Lane 1 is E. guineensis DNA digested with BamHI; Lane 2, E. guineensis DNA digested with EcoRI; Lane 3, E. guineensis DNA digested with HindIII; Lane 4, E. guineensis DNA digested with SpeI. (b) SpeI and HindIII restriction sites in the Egpsy genomic sequence.

suggested that there is only one copy of psy gene in the genome of E. guineensis. The copy number of psy gene in E. guineensis genome was also examined using the available oil palm genome data (http:/ / genomsawit.mpob.gov.my). The search result indicated that there is a single copy of $p s y$ gene in E. guineensis. The gene was predicted to be located on chromosome 16.

Mesocarp tissue is the storage site of carotenoid accumulation in oil palm. Since PSY is the important control point of flux in carotenoid biosynthesis, the expression of its gene should be highly regulated in this tissue. The expression level of psy was examined during oil palm fruit development at weekly-intervals starting from 5 WAA until 19 WAA (Figure 5). The expression of psy in 5 WAA mesocarp tissue was about 1.72 folds higher than the calibrator (13 WAA). The expression increased to about 2.38 folds at 6 WAA, before decreasing to about 1.7 folds at 7 WAA. The psy expression remained at about the same level before decreasing at 10 WAA to about 1.3 folds, rebounded at 11 WAA and reached the peak at about 2.4 folds at 12 WAA. Surprisingly, mRNA level of psy decreased to the lowest level at
13 WAA. At 14 WAA, the psy expression increased and remained at about the same level thereafter. Overall, Egpsy was highly expressed in 6, 11, 12, 17 and 19 WAA as compared to the calibrator. This pattern suggested that Egpsy is involved in early and ripening stages of oil palm carotenoid biosynthesis, which is consistent with the findings from E. oleifera reported by Rasid et al. (2008). Oil synthesis and carotene storage in mesocarp commence at 15 to 16 WAA, reaching a peak at 20WAA (Kaur and Sambanthamurthi, 2008; Singh et al., 2013). In young and mature tissues, the major product of carotegenesis was leaf-like xanthophylls which is mainly lutein and neoxanthin (Tay and Gwendoline, 2006). However, during fruit ripening, the lutein will decrease drastically and shift to carotene, mainly $\alpha$ - and $\beta$-carotene (Kaur and Sambanthamurthi, 2008). The low expression at 13 WAA could possibly be due to the transition from the synthesis of leaflike carotenoids to the formation of carotenes. The expression pattern observed for $p s y$ is also quite similar with the expression of a gene encoding phytochrome-interacting factor (pif). This protein was shown to repress psy and down-regulate the 


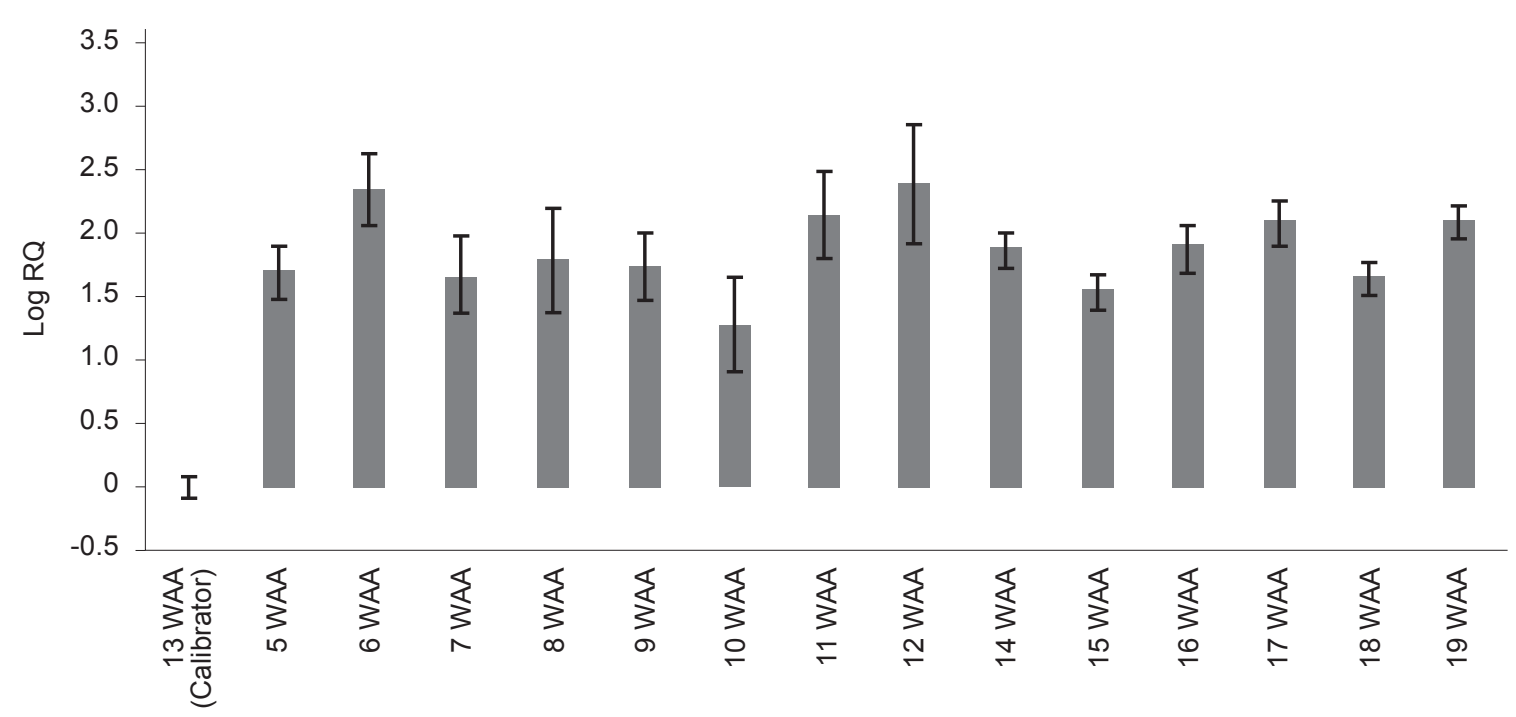

Figure 5. Relative quantities of phytoene synthase (PSY) mRNA in mesocarp tissue of oil palm fruit at different developmental periods. Each week after anthesis (WAA) sample was individually assayed in triplicates. Values shown represent the log Real-Time Quantitative (RQ) and bars indicate the standard error. The expression in the 13 WAA tissue was used as the calibrator.

accumulation of carotenoids (Toledo-Ortiz et al., 2010). Interestingly, the pif gene was concomitant with the gene encoding phytochromes (phy-A, -B, and $-C$ ) in oil palm which was reported to be only expressed at 100 DAP (14 WAA) (Tranbager et al., 2011). Therefore, the expression data of psy could suggest its important role, possibly along with other regulators, in the accumulation of carotenoids in oil palm fruit.

\section{CONCLUSION}

We have isolated a cDNA clone and genomic DNA encoding E. guineensis psy. The sequence of this clone was shown to have high identity to psy sequences from other plants. We also examined its expression patterns during fruit development. The expression of psy was shown to be differentially expressed along the fruit developmental stages. This result suggests that Egpsy may regulate the synthesis and accumulation of carotenoids in the E. guineensis fruit. In essence, the sequence and expression analyses of the psy gene provided useful information for further understanding of its roles in the molecular regulation of carotenoid production and biosynthesis in E. guineensis.

\section{ACKNOWLEDGEMENT}

The authors would like to thank the Director-General of MPOB for permission to present these results. The authors would also like to thank Dr. Abdul Masani Mat Yunus, Siti Masura Subhi and Nor Hanin Ayob, Advanced Biotechnology and Breeding Center, MPOB for reviewing this manuscript.

\section{REFERENCES}

Bourgis, F; Kilaru, A; Cao, X; Ngando-Ebongue, G F; Drira, N; Ohlrogge, J B and Arondel, V (2011). Comparative transcriptome and metabolite analysis of oil palm and date palm mesocarp that differ dramatically in carbon partitioning. Proc. Natl. Acad. Sci. USA, 108(30): 12527-12532.

Buckner, B; Miguel, P S; Janick-Buckner, D and Bennetzen, J L (1996). The y1 gene of maize codes for phytoene synthase. Genetics, 143(1): 479-488.

Busch, M; Sueter, A and Hain, R (2002). Functional analysis of the early steps of carotenoid biosynthesis in tobacco. Plant Physiol., 128(2): 439-453.

Cazzonelli, C I and Pogson, B J (2010). Source to sink: Regulation of carotenoid biosynthesis in plants. Trends Plant Sci., 15(5): 266-274.

Cunningham, F X and Gantt, E (1998). Genes and enzymes of carotenoid biosynthesis in plants. Annu. Rev. Plant. Physiol. Plant. Mol. Biol., 49: 557-583.

Fraser, P D; Roemer, S; Shipton, C A; Mills, P B; Kiano, J W; Misawa, N; Drake, R G; Schuch, W and Bramley, P M (2002). Evaluation of transgenic tomato plants expressing an additional phytoene synthase in a fruit-specific manner. Proc. Natl. Acad. Sci. USA, 99(2): 1092-1097.

Fraser, P D; Schuch, W and Bramley, P M (2000). Phytoene synthase from tomato (Lycopersicon esculentum) chloroplasts-partial purification and biochemical properties. Planta, 211(3): 361369. 
Fraser, P D; Hedden, P M; Cooke, D T; Bird, C R; Schuch, W and Bramley, P M (1995). The effect of reduced activity of phytoene synthase on isoprenoid levels in tomato pericarp during development and ripening. Planta, 196: 321-326.

Fray, R G and Grierson, D (1993). Molecular-genetics of tomato fruit ripening. Trends in Genetics, 9(12): 438-443.

Fray, R G; Wallace, A; Fraser, P D; Valero, D; Hedden, P; Branley, P M and Grierson, D (1995). Constitutive expression of a fruit phytoene synthase gene in transgenic tomatoes causes dwarfism by redirecting metabolites from the gibberellin pathway. Plant J., 8(5): 693-701.

Giuliano, G; Bartley, G E and Scolnik, P A (1993). Regulation of carotenoid biosynthesis during tomato development. Plant Cell, 5(4): 379-387.

Horton, P; Park, K J; Obayashi, T; Fujita, N; Harada, H; Adams-Collier, C J and Nakai, K (2007). WoLF PSORT: Protein localization predictor. Nucleic Acids Res., 35: 585-587.

Huh, J H; Kang, B C; Nahm, S H; Kim, S, Ha, K S; Lee, M H and Kim, B D (2001). A candidate gene approach identified phytoene synthase as the locus for mature fruit colour in red pepper (Capsicum spp.). Theor. Appl. Genet., 102: 524-530.

Karvouni, Z; John, I; Taylor, J E; Watson, C F; Turner, A J and Grierson, D (1995). Isolation and characterisation of a melon cDNA clone encoding phytoene synthase. Plant Mol. Biol., 27(6): 1153-1162.

Kato, M; Ikoma, Y; Matsumoto, H; Sugiura, M; Hyodo, H and Yano, M (2004). Accumulation of carotenoids and expression of carotenoid biosynthetic genes during maturation in citrus fruit. Plant Physiol., 134(2): 824-837.

Kaur, J S and Sambanthamurthi, R (2008). Carotenoid profiles and preliminary investigation on carotenoid biosynthesis in the oil palm (Elaeis guineensis) mesocarp. J. Oil Palm Res., (Malaysia-MIT Biotech Partner Prog.) 2: 108-117.

Khemvong, S and Suvachittanont, W (2005). Molecular cloning and expression of a cDNA encoding 1-deoxy-D-xylulose 5-phosphate synthase from oil palm Elaeis guineensis Jacq. Plant Sci., 169(3): 571-578.

Kim, I J; Ko, K C; Kim, C S and Chung, W (2001). Isolation and expression pattern of a cDNA encoding phytoene synthase in Citrus. J. Plant Physiol., 158(6): 795-800
Kushairi, A; Ong-Abdullah, M; Balu, N; Hishamuddin, E; Izuddin, Z B; Razmah, G; Subramaniam, V; Sundram, S and Parveez, G K A (2019). Oil palm economic performance in Malaysia and R\&D progress in 2018. J. Oil Palm Res., 31(2): 165-194.

Li, F; Vallabhaneni, R; Yu, J; Rocheford, $\mathrm{T}$ and Wutzel, E T (2008). The maize phytoene synthase gene family: Overlapping roles for carotenogenesis in endosperm, photomorphogenesis and thermal stress tolerance. Plant Physiol., 147: 1334-1346.

Lopez-Emparan, A; Quezada-Martinez, D; ZunigaBustos, M; Cifuentes, V; Iniguez-Luy, F and Laura, F M (2014). Functional analysis of the Brassica napus L. phytoene synthase ( $p s y)$ gene family. PLoS ONE, 9: 12 .

Marchler-Bauer, A; Lu, S; Anderson, J B; Chitsaz, F; Derbyshire, M K; DeWeese-Scott, C; Fong, J H; Geer, L Y; Geer, R C; Gonzales, N R; Gwadz, M; Hurwitz, D I; Jackson, J D; Ke, Z; Lanczycki, C J; Lu, F; Marchler, G H; Mullokandov, M; Omelchenko, M V; Robertson, C L; Song, J S; Thanki, N; Yamashita, R A; Zhang, D; Zhang, N; Zheng, C and Bryant, S H (2011). CDD: A conserved domain database for the functional annotation of proteins. Nucleic Acids Res., 39: 225-229.

Mayne, S T (1996). Beta-carotene, carotenoids, and disease prevention in humans. FESEB J., 10: 690-701.

Mlalazi, B; Welsch, R; Namanya, P; Khanna, H; Geijskes, R J; Harrison, M D and Harding, R (2012). Isolation and functional characterisation of banana phytoene synthase genes as potential cisgenes. Planta, 236: 1585-1598.

Misawa, N; Truesdale, M R; Sandmann, G; Fraser, P D; Bird, C; Schuch, W and Bramley, P M (1994). Expression of a tomato cDNA coding for phytoene synthase in Escherichia coli, phytoene formation in vivo and in vitro, and functional analysis of the various truncated gene products. J. Biochem., 116(5): 980-985.

Mustapa, A N; Manan, Z A; Mohd Azizi, C Y; Setianto, W B and Mohd Omar, A K (2011). Extraction of b-carotenes from palm oil mesocarp using subcritical R134a. Food Chem., 125: 262-267.

Nisar, N; Li, L; Lu, S; Khin, N C and Pogson, B J (2015). Carotenoid metabolism in plants. Mol. Plant, 8: 68-82.

Paine, J A; Shipton, C A; Chaggar S; Howells, R M; Kennedy, M J; Vernon, G; Wright, S Y; Hinchliffe, E; Adams, J L; Silverstone, A L and Drake, R 
(2005). Improving the nutritional value of Golden Rice through increased pro-vitamin A content. Nat. Biotechnol., 23: 482-487.

Rasid, O A; Parveez, G K A; Ho, C L; Sambanthamurthi, R and Napis, S (2009). Plant carotenoids: molecular genetics and regulation. J. Oil Palm Res., 21: 588-601.

Rasid, O A; Wan Nur Syuhada, W S; Nor Hanin, A; Masura, S S; Zulqarnain, M; Ho, C L; Sambanthamurthi, R and Suhaimi, N (2008). RT-PCR amplification and cloning of partial DNA sequence coding for oil palm (Elaeis oleifera) phytoene synthase gene. Asia-Pac. J. Mol. Biol. Biotechnol., 16: 17-24.

Rasid, O A; Singh, R; Harikrishna, K and Cheah, S C (2003). Isolation of partial DNA sequence codon for lycopene $\beta$-cyclas from oil palm. Proc. of the 2003 MPOB International Palm Oil Congress. p. 781-788.

Rasid, O A; Singh, R; Sambanthamurthi, R and Cheah, S C (2005). RT-PCR amplification and cloning of partial DNA sequence coding for oil palm (E. guineensis) zeaxanthin epoxidase. Proc. of the 2005 Conference on Biotechnology of Plantation Commodities. Selangor, Malaysia. p. 553.

Ray, J; Moureau, P; Bird, C; Bird, A; Grierson, D; Mauders, M; Truesdale, M; Bramley, P and Schuch, W (1992). Cloning and characterisation of a gene involved in phytoene synthesis from tomato. Plant Mol. Biol., 19: 401-404.

Rodrigo, M J; Marcos, J F and Zacarias, L (2004). Biochemical and molecular analysis of carotenoid biosynthesis in flavedo of orange (Citrus sinensis L.) during fruit development and maturation. J. Agric. Food Chem., 52(22): 6724-6731.

Rose, T M (2005). CODEHOP-mediated PCR A powerful technique for the identification and characterization of viral genomes. Virol J., 15: 20.

Salvini, M; Bernini, A; Fambrini, M and Pugliesi, C (2005). cDNA cloning and expression of the phytoene synthase gene in sunflower. J. Plant Physiol., 162(4): 479-484.

Scolnik, P A and Bartley, G E (1994). Nucleotide sequence of an Arabidopsis cDNA for phytoene synthase. Plant Physiol., 104(4): 1471-1472.

SIB (2020). TMpred webserver. http://www. ch.embnet.org/software/TMPRED_form.html Swiss Institute of Bioinformatics (SIB), accessed on 13 March 2020.

Singh, R; Ong-Abdullah, M; Low, E T; Manaf, M A; Rosli, R; Nookiah, R; Ooi, L C; Ooi, S E; Chan,
K L; Halim, M A; Azizi, N; Nagappan, J; Bacher, B; Lakey, N; Smith, S W; He, D; Hogan, M; Budiman, M A; Lee, E K; DeSalle, R; Kudrna, D; Goicoechea, J L; Wing, R A; Wilson, R K; Fulton, R S; Ordway, J M; Martienssen, R A and Sambanthamurthi, R (2013). Oil palm genome sequence reveals divergence of interfertile species in old and new worlds. Nature, 500: 335-339.

Stewart Jr, C N and Via, L E (1993). A rapid CTAB isolation technique useful for rapid fingerprinting and other PCR application. Biotechniques, 14(5): 748750 .

Tanaka, Y and Ohmiya, A (2008). Seeing is believing: Engineering anrhocyanin and carotenoid biosynthetic pathways. Curr. Opin. Biotechnol., 19(2): 190-197.

Tay, B Y P and Gwendoline, E C L (2006). Identification of lutein in crude palm oil and evaluation of carotenoids at various ripening stages of the oil palm fruit. J. Oil Palm Res., 18: 189197.

Toledo-Ortiz, G; Huq, E and RodríguezConcepcio'n, M (2010). Direct regulation of phytoene synthase gene expression and carotenoid biosynthesis by phytochrome-interacting factors. Proc. Natl. Acad. Sci. USA, 107(25): 11626-11631.

Tranbarger, T J; Dussert, S; Joët, T; Argout, X; Summo, M; Champion, A; Cros, D; Omore, A; Nouy, B and Morcillo, F (2011). Regulatory mechanisms underlying oil palm fruit mesocarp maturation, ripening, and functional specialization in lipid and carotenoid metabolism. Plant Physiol., 156(2): 564584 .

Uenojo, M; Maróstica Júnior, M R and Pastore, G M (2007). Carotenoids: Properties, applications and biotransformation in flavour compounds. Química Nova, 30(3): 616-622.

Wang, J; He, X; He, Z; Wang, H and Xia, X (2009). Cloning and phylogenetic analysis of phytoene synthase 1 (PSY1) genes in common wheat and related species. Hereditas, 146(5): 208-256.

Wan Nur Syuhada, W S; Rasid, O A and Parveez, G K A (2012). Phytoene synthase gene from oil palm (Elaeis oleifera) for modification of carotenoid content. MPOB Information Series No. 600.

Wong, J C; Lambert, R J; Wutzel, E T and Rocheford, T R (2004). QTL and candidate genes phytoene synthase and zeta-carotene associated with the accumulation of carotenoids in maize. Theor. Appl. Genet., 108(2): 349-359. 
Zeng, Y and Yang, T (2002). RNA isolation from highly viscous samples rich in polyphenols and polysaccharides. Plant Mol. Bio. Rep., 20: 415-417.

Zhang, L; Zhang, Z; Zheng, T; Wei, W; Zhu, Y; Gao, Y; Yang, X and Lin, S (2016). Characterization of carotenoid accumulation and carotenogenic gene expression during fruit development in yellow and white loquat fruit. Hortic. Plant J., 2(1): 9-15.

Zviling, M; Kochva, U and Arkin, I T (2007). How important are transmembrane helices of bitopic membrane proteins? Biochim. Biophys. Acta, 1768(3): 387-392. 